\title{
Short communication: Identification of coagulase-negative staphylococcus species from goat milk with the API Staph identification test and with transfer RNA-intergenic spacer PCR combined with capillary electrophoresis
}

\author{
G. Koop, ${ }^{\star}$ A. De Visscher,† C. A. Collar,‡ D. A. C. Bacon,§ E. A. Maga,\# J. D. Murray,\#॥l K. Supré,卂 \\ S. De Vliegher,† F. Haesebrouck, ${ }^{* \star}$ J. D. Rowe,II M. Nielen, ${ }^{*}$ and T. van Werven* \\ *Department of Farm Animal Health, Faculty of Veterinary Medicine, Utrecht University, Utrecht, $3584 \mathrm{CL}$, the Netherlands \\ †M-Team and Mastitis and Milk Quality Research Unit, Department of Reproduction, Obstetrics, and Herd Health, Faculty of Veterinary Medicine, \\ Ghent University, Merelbeke, B-9820, Belgium \\ ‡University of California Cooperative Extension Kings County, Hanford 93230 \\ §University of California Cooperative Extension Tulare County, Tulare 93274 \\ \#Department of Animal Science, University of California, Davis 95616 \\ IIDepartment of Population Health and Reproduction, University of California, Davis 95616 \\ IMilk Control Center Flanders, Lier, B-2500, Belgium \\ ${ }^{\star *}$ Department of Pathology, Bacteriology, and Avian Diseases, Faculty of Veterinary Medicine, Ghent University, Merelbeke, B-9820, Belgium
}

\begin{abstract}
Coagulase-negative staphylococci (CNS) are the most commonly isolated bacteria from goat milk, but they have often been identified with phenotypic methods, which may have resulted in misclassification. The aims of this paper were to assess the amount of misclassification of a phenotypic test for identifying CNS species from goat milk compared with transfer RNA intergenic spacer PCR (tDNA-PCR) followed by capillary electrophoresis, and to apply the tDNA-PCR technique on different capillary electrophoresis equipment. Milk samples were collected from 416 does in 5 Californian dairy goat herds on 3 occasions during lactation. In total, 219 CNS isolates were identified at the species level with tDNA-PCR and subjected to the API 20 Staph identification test kit (API Staph; bioMérieux, Durham, NC). If the same species was isolated multiple times from the same udder gland, only the first isolate was used for further analyses, resulting in 115 unique CNS isolates. According to the tDNA-PCR test, the most prevalent CNS species were Staphylococcus epidermidis, Staphylococcus caprae, and Staphylococcus simulans. Typeability with API staph was low (72\%). Although the API Staph test was capable of identifying the majority of Staph. epidermidis and Staph. caprae isolates, sensitivity for identification of Staph. simulans was low. The true positive fraction was high for the 3 most prevalent species. It was concluded that the overall performance of API Staph in differentiating CNS species from goat milk was moderate to low, mainly
\end{abstract}

Received May 18, 2012.

Accepted August 12, 2012.

${ }^{1}$ Corresponding author: g.koop@uu.nl because of the low typeability, and that genotypic methods such as tDNA-PCR are preferred.

Key words: coagulase-negative Staphylococcus species, goat, transfer DNA-PCR, API 20 Staph identification test

\section{Short Communication}

In dairy goats, CNS species are often the cause of subclinical IMI (Bergonier et al., 2003; Contreras et al., 2007). The CNS species that have been isolated the most frequently from goat milk are Staphylococcus epidermidis, Staphylococcus caprae, and Staphylococcus simulans (e.g., Deinhofer and Pernthaner, 1995; Leitner et al., 2004; Moroni et al., 2005), but many more species have been identified. In a recent publication (Koop et al., 2012), we showed that CNS species in goats differ in their effect on milk yield, indicating that some species may be more pathogenic than others. Furthermore, in cattle, differences were described between CNS species in the effect on SCC (Supré et al., 2011), mode of transmission (environmental vs. contagious; Piessens et al., 2012), potential reservoir (Piessens et al., 2011), and susceptibility to antibiotics (Sampimon et al., 2007). Therefore, correct differentiation of CNS species is important. Still, most studies on CNS in goats have used phenotypic methods to identify the different species. Several research groups have studied how phenotypic identification methods relate to genotypic methods in CNS cultured from cow's milk (Sampimon et al., 2009; Park et al., 2011) and from sheep milk (Onni et al., 2010), and have described poor performance of phenotypic tests in CNS isolates from these animal species. Recently, the first comparison of a genotypic (PCR-RFLP of the groEL gene) and a phenotypic [API 20 Staph ID test kit (API staph); bio- 
Mérieux, Durham, NC] method in CNS from goat milk was described (Onni et al., 2012). This study concluded that the phenotypic method misidentifies a significant number of isolates, but estimates of test characteristics of phenotypic tests for CNS from goat's milk were not reported. Ruegg (2009) argued that the use of phenotypic methods to differentiate CNS species in practice can be seen as a first step to enhance knowledge about the role of CNS, but estimates of sensitivity, specificity, and the true positive fraction of phenotypic tests relative to a genotypic gold standard test are needed to interpret phenotypic test results obtained in practice and reported in the available literature.

Transfer RNA-intergenic spacer PCR (tDNA-PCR) is an accurate, inexpensive, and easy-to-use method of identifying CNS species (Supré et al., 2009) that uses length polymorphisms of the intergenic spacers between transfer RNA genes to differentiate between species. This technique uses capillary electrophoresis (CE) rather than gel electrophoresis to enhance discriminatory power. A fingerprint library is used to compare patterns of unidentified isolates with known isolates. This technique is supposedly sensitive to changes in the apparatus and polymer used for the CE, but with newer $\mathrm{CE}$ equipment being developed, it is important to assess how the tDNA-PCR technique can be adapted to be applied on newer CE equipment.

In this study, CNS isolates cultured from caprine milk samples collected in a field study in California were subjected to a modified protocol of the tDNAPCR and to the API staph test. The performance of the tDNA-PCR technique with different $\mathrm{CE}$ equipment was assessed by comparison with the original protocol and by gene sequencing. The goals of the study were to calculate sensitivity, specificity, and the true positive fraction of the API staph test relative to tDNA-PCR identification, and to adapt the tDNA-PCR technique to a newer CE machine and polymer.

A longitudinal prospective field study was performed in California. A total of 416 does were enrolled on 5 dairy goat farms. Farms were selected based on their participation in the DHIA milk testing and recording program. Criteria to enroll goats were that the goats were intended to be kept in the herd for that entire lactation and that the goats had complete records (kidding date, breed, and lactation number). Foremilk samples were collected aseptically from both udder halves at early, mid, and late lactation in the milking parlor during the morning milking. The samples were frozen at $-20^{\circ} \mathrm{C}$ until bacteriological culture, which was performed within 5 to $7 \mathrm{~d}$ at the University of California Milk Quality Laboratory at the Veterinary Medicine Teaching and Research Center (Tulare, CA).
In short, $0.01 \mathrm{~mL}$ of milk was streaked onto one-half of a trypticase soy agar plate with $5 \%$ sheep blood and incubated for 18 to $24 \mathrm{~h}$ at 35 to $37^{\circ} \mathrm{C}$. Bacteria were classified following National Mastitis Council guidelines (Hogan et al., 1999). In total, 219 CNS isolates were stored in trypticase soy broth with $15 \%$ (wt/vol) glycerol at $-80^{\circ} \mathrm{C}$ until further identification with the genotypic method.

All CNS isolates were subjected to tDNA-PCR, as described below, which was the reference (gold standard) test. Because goats were sampled repeatedly and because CNS can cause persistent infections (Contreras et al., 1997; Koop et al., 2012), it was likely that multiple isolates of the same species cultured from an udder half belonged to the same strain. Therefore, if the same species (according to the tDNA-PCR identification) was isolated multiple times from the same udder half, only the first isolate was used for further analyses. In addition, samples that could not be identified with certainty with tDNA-PCR $(\mathrm{n}=2)$ were excluded from the analyses. In this way, 115 unique CNS isolates remained for comparison with the API staph identification method.

The 219 CNS isolates were regrown on sheep blood agar plates. One colony from each plate was added to a vial with $5 \mathrm{~mL}$ of brain heart infusion broth and incubated overnight at $37^{\circ} \mathrm{C}$. From these cultures, DNA was extracted according to the method of Ünal et al. (1992), with one modification: instead of a $100 \mu \mathrm{g} / \mathrm{mL}$ lysostaphin solution (Sigma-Aldrich, St. Louis, MO), a $50 \mu \mathrm{g} / \mathrm{mL}$ solution was used. The DNA was frozen at $-20^{\circ} \mathrm{C}$ until further use.

The CNS species were identified using tDNA-PCR followed by capillary electrophoresis as described by Supré et al. (2009) with some modifications: an ABI Prism 3100 Genetic Analyzer and Performance Optimized Polymer 6 (Applied Biosystems, Foster City, CA) were used instead of the ABI Prism 310 Genetic Analyzer and Performance Optimized Polymer 4 (Applied Biosystems). Furthermore, the primers were labeled with FAM dye instead of TET dye (Applied Biosystems). Finally, the results from $\mathrm{CE}$ were interpreted using STRand software (UC Davis Veterinary Genetics Laboratory, Davis, CA) instead of GeneScan software (Applied Biosystems). The tDNA patterns that were obtained for each isolate were compared with the tDNA library constructed by Supré et al. (2009).

We expected that the use of a different $\mathrm{CE}$ machine and polymer would cause a deviation from the results obtained with the equipment used for construction of the tDNA library. Therefore, patterns that were observed frequently were first visually compared with patterns from the existing tDNA library. In this way, 
species were identified tentatively and the degree to which a shift in the pattern had occurred relative to the patterns from the existing library could be assessed. A correction was made for all isolates by subtracting the difference in base pairs between the obtained patterns and the patterns from the library from the obtained fragment lengths. After this correction, patterns were compared with the existing library and a distance matrix was calculated using the software described by Supré et al. (2009). On the basis of this distance matrix, dendrograms were visualized with TreeView software (Page, 1996). Different clusters were seen in the dendrograms, and identification was assigned to all clusters of isolates. The DNA of 1 or 2 samples from each cluster in the dendrogram (30 samples in total) was shipped to the Faculty of Veterinary Medicine of Ghent University (Merelbeke, Belgium) for confirmation of the identification using tDNA-PCR with the original $\mathrm{CE}$ machine and polymer as described by Supré et al. (2009). If a confirmation isolate could not be identified with certainty using the original tDNA-PCR, sequencing of the rpoB gene (Supré et al., 2009) was performed and the tDNA library was updated with these results.

The 115 unique CNS isolates were subjected to the API staph test according to the method of Park et al. (2011). Identification with a probability of $\geq 90 \%$ was considered acceptable, and isolates with a lower probability were considered unidentified. In addition, we tested a cutoff value of $\geq 75 \%$ probability.

We compared the results from the API staph method with the results from the modified tDNA-PCR protocol and expressed the functioning of the phenotypic test relative to the DNA-based test in terms of sensitivity, specificity, and true positive fraction following the method of Sampimon et al. (2009). Sensitivity was defined as the fraction of all isolates identified as a certain species with tDNA-PCR that was identified with API staph as that species. Specificity was defined as the fraction of all isolates that were identified as not being a particular species with tDNA-PCR that were identified as not that species with API staph. The true positive fraction was defined as the fraction of isolates identified as a particular species with API staph that was identified as that species with tDNA-PCR. Sensitivity, specificity, and the true positive fraction were calculated with and without isolates that could not be identified with API staph.

Confidence intervals around fractions were calculated using the Wilson method of the binconf function from the Hmisc library (Harrell, 2004) in R software (version 2.13.0; R Foundation for Statistical Computing, Vienna, Austria).

The fragment lengths obtained with the modified tDNA-PCR protocol were approximately 0.8 base pairs higher than in the library based on the original protocol. After transformation of the results by subtracting 0.8 base pairs from the obtained fragment lengths, the isolates could be identified with the library, but the matches were not as good as for isolates analyzed with the original equipment. Of the 30 confirmation isolates, the original tDNA-PCR protocol yielded inconclusive results for 7 isolates (23\%), which were identified after gene sequencing. Of these 30 isolates, 20 identifications matched the initial identification with the modified tDNA-PCR protocol. These 20 isolates represented the clusters that comprised 195 of the 219 isolates and 103 of the 115 unique isolates. The 10 isolates that did not match the identification of the modified tDNA-PCR protocol belonged to smaller clusters, which were now identified based on the confirmation isolates: clusters of 18 isolates in total that were initially identified as Staphylococcus equorum and Staphylococcus croceolyticus turned out to be Staphylococcus xylosus after confirmation using gene sequencing. One cluster of 3 isolates that was identified as Staphylococcus auricularis turned out to be Staphylococcus gallinarum. One isolate that was somewhat related to a cluster of Staphylococcus chromogenes but could not be identified with certainty turned out to be Staph. pasteuri after gene sequencing. Finally, 2 isolates were initially identified as Staphylococcus rostri with the modified tDNA-PCR protocol, but no isolates from this small cluster were sent out for confirmation, so a definitive identification could not be made and these isolates were analyzed as unidentified. In this way, gene sequencing was used to update the tDNA-PCR results, which could then be used as the gold standard test.

Table 1 shows how the API staph identification relates to tDNA-PCR identification in terms of sensitivity, specificity, and the true positive fraction, based on the 115 unique CNS isolates. If a particular species was not identified with tDNA-PCR (the gold standard test) but was identified with API staph, then specificity and the true positive fraction were reported, but no value for sensitivity could be calculated. Conversely, if a species was identified with tDNA-PCR but was never identified with API staph, sensitivity and specificity could be calculated, but the true positive fraction could not be calculated. Of all 115 unique isolates that were subjected to the API staph test, only 83 (typeability = $72 \%$ ) were identified with a probability of $\geq 90 \%$. The test properties of API staph were strongly dependent on whether unidentified isolates were included in the calculations. For the 3 most prevalent species (Staph. epidermidis, Staph. caprae, and Staph. simulans), the true positive fraction of API staph identification was 1. Specificity for these species was also 1, but this number decreased when unidentified isolates were taken into 
account. Sensitivity for Staph. caprae and Staph. epidermidis was also estimated to be higher than 0.90, but was only 0.33 for Staph. simulans. Even when unidentified isolates were included, sensitivity for Staph. epidermidis was 1 , but sensitivity was moderate (0.78) for Staph. caprae and low (0.09) for Staph. simulans. Other species were detected less frequently; therefore, sensitivity and the true positive fraction could be estimated with little precision.

The fraction of samples for which the API staph did not give an identification was large, although the typeability was higher than in the study by Sampimon et al. (2009) on CNS from cow milk samples, in which 80 out of 172 isolates were unidentified, corresponding to a typeability of $53 \%$. When these unidentified samples were taken into account, we found lower sensitivity and especially lower specificity, as was expected. This means that as long as it is unknown whether the API staph will give a result, for instance when one has to decide whether to use this test, the expected test characteristics are moderate because of the low typeability. When a result has been obtained, the test characteristics are better. The true positive fraction of API staph relative to tDNA-PCR was good for the most prevalent (based on tDNA-PCR) CNS species, and sensitivity of API staph was acceptable for Staph. epidermidis and Staph. caprae but was low for Staph. simulans. This means that for detecting Staph. epidermidis and Staph. caprae, the API staph test may be valuable, but other species will frequently be misclassified or unidentified, making the API staph a poor tool for identification of caprine CNS species. In a veterinary practice, API staph may be the only available tool for differentiating CNS species. However, because of the high probability of misclassification, we do not recommend using it unless the sole goal would be to differentiate among Staph. caprae, Staph. epidermidis, and other CNS species.

Onni et al. (2012) compared the performance of API staph on CNS from goat milk with PCR-RFLP of the groEL gene. On the basis of their report, we could calculate sensitivity, specificity, and the true positive fraction for the isolated species. Test characteristics for Staph. caprae and Staph. epidermidis were comparable with what we reported. However, API staph had a much higher sensitivity for Staph. simulans in their study: 7 out of 8 Staph. simulans isolates were identified correctly (sensitivity $=0.88$ ). This may have to do with the fact that Onni et al. (2012) did not exclude API staph results based on a low probability of correct identification as given by the API software. In our data, we observed that of the 14 isolates identified as Staph. simulans with API staph, only 2 had a probability of $\geq 90 \%$. However, of the remaining 12 isolates, 11 were identified correctly. This implies that the certainty of

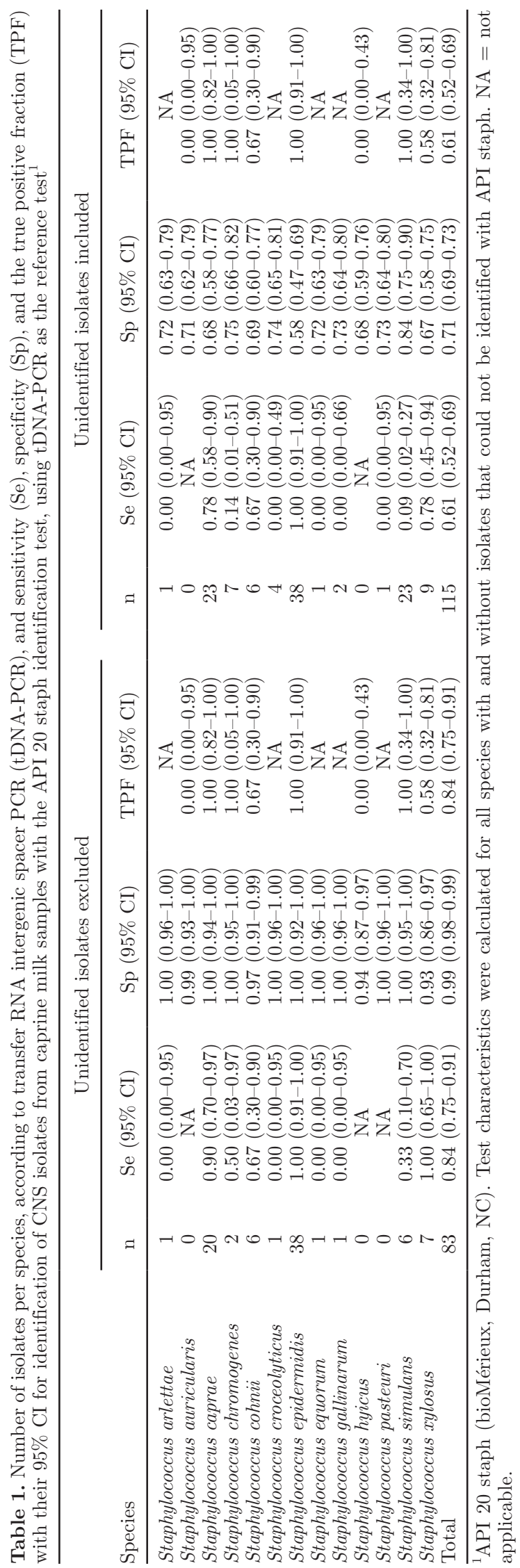

Journal of Dairy Science Vol. 95 No. 12, 2012 
identification of Staph. simulans is underestimated. Even when a probability of $\geq 75 \%$ was used as a cutoff value, only 4 more Staph. simulans isolates were identified with API staph. The 8 remaining Staph. simulans isolates had a probability of $<60 \%$. Also for the other isolates, the effect of lowering the cutoff value for identification was limited. At a cutoff value of $\geq 75 \%, 94$ of the 115 isolates were classified as identified (compared with 83 at $\geq 90 \%$ ), resulting in a typeability of $82 \%$ and in a somewhat higher sensitivity for Staph. chromogenes and Staph. simulans and in a slightly lower specificity for Staph. epidermidis.

One previous paper compared the API staph method with ribotyping for identifying Staph. caprae cultured from goat milk (Bedidi-Madani et al., 1998). This study, however, used an older version of the API staph method, with 19 substrates. Other research has compared the API staph test with genotypic methods for CNS species cultured from cow or sheep milk. Our results for Staph. epidermidis and Staph. caprae were in line with observations by Sampimon et al. (2009) and Onni et al. (2010). For Staph. simulans, Sampimon et al. (2009) reported low sensitivity, as was found in our study, but the true positive fraction was lower in their study than in the present investigation. For Staph. xylosus, both Sampimon et al. (2009) and Onni et al. (2010) reported a somewhat lower true positive fraction (0.52 and 0.36 , respectively) and a sensitivity comparable with what was found in our study. The fact that, in our study, Staphylococcus hyicus had been misidentified in all 5 cases was surprising because in 2 studies in cows, identification of Staph. hyicus was always correct using the API 32 staph ID test (Sampimon et al., 2009) and the API staph test (Park et al., 2011). However, Zadoks and Watts (2009) also reported low specificity for Staph. hyicus from heifer milk in the United States when using the API staph test. Apparently, some Staph. simulans, Staph. chromogenes, and Staph. caprae strains exist in goats that have similar biochemical characteristics as Staph. hyicus.

We showed in this study that when the tDNA-PCR technique was performed with different equipment, the resulting tDNA patterns had to be transformed for correct interpretation. By reanalyzing several isolates from all identified clusters, all isolates could be identified with certainty. Without this confirmation step, 24 of the 219 isolates would have been identified incorrectly. Confirmation of isolates is costly and time consuming, which means that if larger numbers of samples are to be analyzed on a different $\mathrm{CE}$ apparatus or with a different polymer, construction of a new library may be more efficient. The tDNA-PCR technique is a valuable technique because of its high accuracy, fast throughput time, and low cost (Supré et al., 2009). Currently, gene sequencing is generally more expensive and labor demanding. However, the advantages of gene sequencing over the technique used for this paper are the availability of a larger reference database and the fact that it gives a quantitative measure of the certainty with which an isolate has been identified (Zadoks and Watts, 2009).

This study showed that API staph can be used to identify Staph. epidermidis and Staph. caprae, but its general functioning in CNS from goat milk samples is poor, mostly because of the low typeability. Genotypic methods are more appropriate. The tDNA-PCR proved to be a useful technique but was sensitive to changes in materials and equipment.

\section{ACKNOWLEDGMENTS}

Kathy Glenn and Karen Tonooka (Milk Quality Laboratory, Veterinary Medicine Teaching and Research Center, University of California, Tulare) are acknowledged for culturing the milk samples and for their great support during the DNA extractions. Amy Young (Bannasch Laboratory, University of California, Davis) is gratefully acknowledged for her skillful assistance with the capillary electrophoresis work. We thank Cecilia Penedo (Veterinary Genetics Laboratory, University of California, Davis), who was of great help with the interpretation of the capillary electrophoresis data and kindly provided access to the STRand software. We are most grateful to J. S. Cullor (Veterinary Medicine Teaching and Research Center, School of Veterinary Medicine, University of California, Davis) for initiating contact between the Dutch and Californian researchers. This research was financially supported by the National Sheep Industry Improvement Center (Rockland, ME), the American Dairy Goat Association (Spindale, NC), the Dutch Dairy Board (Zoetermeer, the Netherlands) and the Dutch Association for Quality Assurance in Goat Farming (VKGN, Giessenburg, the Netherlands).

\section{REFERENCES}

Bedidi-Madani, N., A. Kodjo, L. Villard, and Y. Richard. 1998. Ribotyping of Staphylococcus caprae isolated from goat milk. Vet. Res. 29:149-158.

Bergonier, D., R. de Cremoux, R. Rupp, G. Lagriffoul, and X. Berthelot. 2003. Mastitis of dairy small ruminants. Vet. Res. 34:689-716.

Contreras, A., J. C. Corrales, A. Sánchez, and D. Sierra. 1997. Persistence of subclinical intramammary pathogens in goats throughout lactation. J. Dairy Sci. 80:2815-2819.

Contreras, A., D. Sierra, A. Sánchez, J. C. Corrales, J. C. Marco, M. J. Paape, and C. Gonzalo. 2007. Mastitis in small ruminants. Small Rumin. Res. 68:145-153.

Deinhofer, M., and A. Pernthaner. 1995. Staphylococcus spp. as mastitis-related pathogens in goat milk. Vet. Microbiol. 43:161-166.

Harrell, F. E. 2004. Hmisc S function library. Department of Biostatistics, Vanderbilt University, Nashville, TN. Accessed Aug. 12, 2012. http://biostat.mc.vanderbilt.edu/s/Hmisc. 
Hogan, S. J., R. N. González, R. J. Harmon, S. C. Nickerson, S. G. Oliver, J. W. Pankey, and K. L. Smith. 1999. Laboratory Handbook on Bovine Mastitis. Rev. ed. Natl. Mastitis Counc., Verona, WI.

Koop, G., S. De Vliegher, A. De Visscher, K. Supré, F. Haesebrouck, M. Nielen, and T. van Werven. 2012. Differences between coagulase-negative Staphylococcus species in persistence and in effect on somatic cell count and milk yield in dairy goats. J. Dairy Sci. 95 :5075-5084.

Leitner, G., U. Merin, and N. Silanikove. 2004. Changes in milk composition as affected by subclinical mastitis in goats. J. Dairy Sci. 87:1719-1726.

Moroni, P., G. Pisoni, M. Antonini, G. Ruffo, S. Carli, G. Varisco, and P. Boettcher. 2005. Subclinical mastitis and antimicrobial susceptibility of Staphylococcus caprae and Staphylococcus epidermidis isolated from two Italian goat herds. J. Dairy Sci. 88:1694-1704.

Onni, T., G. Sanna, G. P. Cubeddu, G. Marogna, S. Lollai, G. Leori, and S. Tola. 2010. Identification of coagulase-negative staphylococci isolated from ovine milk samples by PCR-RFLP of $16 \mathrm{~S}$ rRNA and gap genes. Vet. Microbiol. 144:347-352.

Onni, T., A. Vidili, E. Bandino, G. Marogna, S. Schianchi, and S. Tola. 2012. Identification of coagulase-negative staphylococci isolated from caprine milk samples by PCR-RFLP of groEL gene. Small Rumin. Res. 104:185-190.

Page, R. D. M. 1996. Treeview: An application to display phylogenetic trees on personal computers. Comput. Appl. Biosci. 12:357-358.

Park, J. Y., L. K. Fox, K. S. Seo, M. A. McGuire, Y. H. Park, F. R. Rurangirwa, W. M. Sischo, and G. A. Bohach. 2011. Comparison of phenotypic and genotypic methods for the species identification of coagulase-negative staphylococcal isolates from bovine intramammary infections. Vet. Microbiol. 147:142-148.

Piessens, V., S. De Vliegher, B. Verbist, G. Braem, A. Van Nuffel, L. De Vuyst, M. Heyndrickx, and E. Van Coillie. 2012. Intra-species diversity and epidemiology varies among coagulase-negative Staphylococcus species causing bovine intramammary infections. Vet. Microbiol. 155:62-71.
Piessens, V., E. Van Coillie, B. Verbist, K. Supré, G. Braem, A. Van Nuffel, L. De Vuyst, M. Heyndrickx, and S. De Vliegher. 2011. Distribution of coagulase-negative Staphylococcus species from milk and environment of dairy cows differs between herds. J. Dairy Sci. 94:2933-2944.

Ruegg, P. L. 2009. The quest for the perfect test: Phenotypic versus genotypic identification of coagulase-negative staphylococci associated with bovine mastitis. Vet. Microbiol. 134:15-19.

Sampimon, O. C., J. C. A. Vernooij, D. J. Mevius, and J. Sol. 2007. Sensitivity to various antibiotics of coagulase-negative staphylococci isolated from samples of milk from Dutch dairy cattle. Tijdschr. Diergeneeskd. 132:200-204.

Sampimon, O. C., R. N. Zadoks, S. De Vliegher, K. Supré, F. Haesebrouck, H. W. Barkema, J. Sol, and T. J. G. M. Lam. 2009. Performance of API Staph ID 32 and Staph-Zym for identification of coagulase-negative staphylococci isolated from bovine milk samples. Vet. Microbiol. 136:300-305.

Supré, K., S. De Vliegher, O. C. Sampimon, R. N. Zadoks, M. Vaneechoutte, M. Baele, E. De Graef, S. Piepers, and F. Haesebrouck. 2009. Technical note: Use of transfer RNA-intergenic spacer PCR combined with capillary electrophoresis to identify coagulase-negative Staphylococcus species originating from bovine milk and teat apices. J. Dairy Sci. 92:3204-3210.

Supré, K., F. Haesebrouck, R. N. Zadoks, M. Vaneechoutte, S. Piepers, and S. De Vliegher. 2011. Some coagulase-negative Staphylococcus species affect udder health more than others. J. Dairy Sci. 94:2329-2340.

Ünal, S., J. Hoskins, J. E. Flokowitsch, C. Y. E. Wu, D. A. Preston, and P. L. Skatrud. 1992. Detection of methicillin-resistant staphylococci by using the polymerase chain reaction. J. Clin. Microbiol. 30:1685-1691.

Zadoks, R. N., and J. L. Watts. 2009. Species identification of coagulase-negative staphylococci: Genotyping is superior to phenotyping. Vet. Microbiol. 134:20-28. 